\title{
Interaction of Primate Alveolar Macrophages and Legionella pneumophila
}

\author{
Richard F. Jacobs, Richard M. Locksley, \\ Christopher B. Wilson, Joel E. Haas, and \\ Seymour J. Klebanoff \\ Departments of Pediatrics, Medicine, and Pathology, University \\ of Washington School of Medicine, Children's Orthopedic \\ Hospital and Medical Center, Seattle, Washington 98105
}

bstract. We studied the interaction between Legionella pneumophila, which is principally a pulmonary pathogen, with primate alveolar macrophages (AM), which are the primary pulmonary cellular defense mechanism. For these studies we used $L$. pneumophila, type I, which were grown in albumin-yeast extract broth, were $>80 \%$ viable, and were comparable in virulence for guinea pigs to organisms from guinea pig spleen homogenates. For comparison, avirulent agar-passed L. pneumophila, type I, and a strain of Escherichia coli were also used. In the absence of detectable antibody, AM phagocytosed similar numbers of virulent and avirulent Legionella and killed the majority of ingested Legionella in 15-30 min, as determined by two different assays. The virulent and avirulent Legionella appeared to be equally susceptible to the cidal systems of the AM and both were killed more readily than were $E$. coli under both assay conditions. Phagocytosis of Legionella by AM was associated with a localized respiratory burst, as indicated by nitroblue tetrazolium reduction around ingested organisms. Killing of AM-associated Legionella was inhibited by the hydroxyl radical $(\mathrm{OH} \cdot$ ) scavenger mannitol (but not by an equiosmolar concentration of sodium sulfate), and by a combination of superoxide dismutase and catalase (but not by either enzyme alone). These findings suggest a contribution by $\mathrm{OH} \cdot$, one generated by the metal-catalyzed interaction of superoxide and hydrogen peroxide (HaberWeiss reaction) in the anti-Legionella activity of AM.

Dr. Jacobs is supported by a fellowship from the American Lung Association. Dr. Wilson is a John A. and George L. Hartford Fellow. Address reprint requests to Dr. Wilson, Division of Infectious Diseases. 1984.

Received for publication 27 May 1982 and in revised form 22 February

J. Clin Invest.

(c) The American Society for Clinical Investigation, Inc. 0021-9738/84/06/1515/09 $\$ 1.00$

Volume 73, June 1984, 1515-1523
The virulent Legionella that survived intracellularly increased in number from $4 \times 10^{4}$ at $1 \mathrm{~h}$ to $6 \times 10^{6}$ at $96 \mathrm{~h}$ after infection. In contrast, avirulent Legionella replicated more slowly, increasing in number from $4 \times 10^{4}$ to $1 \times 10^{5}$ over the same period. Replication of virulent Legionella destroyed the AM monolayers by $120 \mathrm{~h}$, whereas monolayers containing avirulent organisms remained intact. Thus, virulence of Legionella appears not to correlate with its ability to survive early killing by AM, but rather with the ability of the small fraction of surviving organisms to replicate within these cells.

\section{Introduction}

The lung is the primary site of infection in Legionnaire's disease, which is caused by the fastidious gram-negative bacterium, Legionella pneumophila $(1,2)$. Pathologically, fatal cases are characterized by alveolar consolidation with a mixed inflammatory infiltrate of alveolar macrophages (AM) ${ }^{1}$ and granulocytes (3, 4). Large numbers of Legionella are observed within AM, which suggests that Legionella might survive and replicate within these cells. This was supported by the important observation of Horwitz and Silverstein (5) that virulent Legionella replicate within human monocytes in vitro. Electron microscopic confirmation of Legionella replication within alveolar and peritoneal macrophages from laboratory animals has been provided (6-8). This and other data demonstrating the replication of Legionella in fibroblasts $(9)$ and in complex artificial media $(10,11)$ indicate that this bacterium is a facultative, intracellular pathogen.

Granulocytes play a role in the early response of the lung to infection (12); their role in early defense against Legionella, however, may be limited, since granulocytes phagocytose Legionella poorly in the absence of specific antibody (13). Antibody has not been detected in the serum of most patients during the

1. Abbreviations used in this paper: AM, alveolar macrophage; AYE, albumin-yeast extract; cfu, colony-forming units; FCS, fetal calf serum; M199, Medium 199; M199+FCS, Medium 199 + 10\% fetal calf serum; NBT, nitroblue tetrazolium; PBSG, phosphate-buffered saline containing $0.1 \%$ gelatin; SOD, superoxide dismutase. 
first week of illness (14). Mononuclear phagocytes can phagocytose $L$. pneumophila in the absence of antibody $(5,15)$. These data, which support the histopathologic observations noted above, suggest that AM are the principal, initial cellular defense against Legionella in acutely infected patients. Previous studies of the interaction of this organism with phagocytes have employed organisms grown in eggyolk sac, a large fraction of which appear to be nonviable $(5,13,15,16)$. We have found that Legionella grown in a modified broth medium are $>80 \%$ viable and are equal in virulence for guinea pigs to the same strain of organisms from guinea pig spleen homogenates (17). We have used such organisms to examine phagocytosis, initial killing, and subsequent replication of $L$. pneumophila type I in primate $\mathrm{AM}$, and have compared these results to those obtained with an avirulent strain of this organism.

\section{Methods}

Reagents. Special reagents were purchased as follows: Hank's balanced salt solution (HBSS) with and without $\mathrm{Ca}^{++}$and $\mathrm{Mg}^{++}$, Medium 199 (M199), L-glutamine, penicillin G, and streptomycin from Gibco Laboratories, Grand Island, NY; fetal calf serum (FCS) from Sterile Systems, Inc., Logan, UT; Diff-Quik stain from the Harleco Co., Dade Diagnostics, Aguada, PR; 2-([2-amino-2-oxoenthyl]amino)-ethanesulfonic acid, fraction $\mathrm{V}$ bovine serum albumin, nitroblue tetrazolium (NBT), zymosan A, superoxide dismutase (SOD, $2.5 \mathrm{mg} / \mathrm{ml} ; 2,800 \mathrm{U} / \mathrm{mg}$ protein), and catalase $(2.5 \mathrm{mg} / \mathrm{ml} ; 34,000$ Sigma U/mg protein) from Sigma chemical Co., St. Louis, MO; yeast extract and agar (Bactoagar) from Difco Laboratories Inc., Detroit, MI; L-cysteine hydrochloride from CalbiochemBehring Corp., La Jolla, CA; $\left.{ }^{35} \mathrm{~S}\right] \mathrm{L}$-cysteine $(46 \mathrm{mCi} / \mathrm{mmol})$ from Amersham Co., Arlington Heights, IL; and $\left[{ }^{14} \mathrm{C}\right]$ leucine $(348 \mathrm{mCi} / \mathrm{mmol})$ from New England Nuclear, Boston, MA. Ferric pyrophosphate and rabbit fluorescein-conjugated anti- $L$. pneumophila antiserum were obtained from the Center for Disease Control, Atlanta, GA and fluoresceinconjugated, anti-bovine antiserum was obtained from Burroughs Wellcome Co., Research Triangle Park, NC.

AM preparations. Adult Macaca nemestrina (pigtail monkey) were anesthetized with intravenous pentobarbitol and sacrificed by exsanguination. The thorax was opened and the trachea was exposed and clamped. A sterile cannula was placed in the trachea and secured with a ligature. The lungs were lavaged seven consecutive times with cold $\left(4^{\circ} \mathrm{C}\right), 0.9 \%$ sodium chloride in $100-500 \mathrm{ml}$ vol. Cells were collected by centrifugation at $200 \mathrm{~g}$ for $10 \mathrm{~min}$, and washed once in HBSS without $\mathrm{Ca}^{++}$or $\mathrm{Mg}^{++}$by centrifugation at $200 \mathrm{~g}$ for $10 \mathrm{~min}$. The cells were then resuspended in M199 that was supplemented with $2 \mathrm{mM}$ L-glutamine, $100 \mathrm{U} / \mathrm{ml}$ penicillin G, $100 \mu \mathrm{g} / \mathrm{ml}$ streptomycin, and $10 \%$ FCS (M199+FCS). Cells were counted in a hemacytometer and viability was determined by trypan blue dye exclusion. The percentage of macrophages was determined by uptake of neutral red dye (18) and by staining for nonspecific esterase (19). The percentage of monocytes and granulocytes was determined by staining for myeloperoxidase (20) and by the morphology of Diff-Quik stained cells. The cells recovered were $>95 \%$ viable, as measured by trypan blue dye exclusion; $\sim 84 \%$ of cells were AM, $<5 \%$ were granulocytes and monocytes, and the remaining cells were lymphocytes and epithelial cells. Suspensions were adjusted to contain $1 \times 10^{6} \mathrm{AM} / \mathrm{ml}$ in M199+FCS. Serum from each of the animals used in these experiments and the FCS were negative (titer $<1: 32$ ) for anti-
Legionella pneumophila type I antibody, measured by indirect immunofluorescence and performed as described (21), except that measurement in FCS was modified by the use of fluorescein-conjugated, anti-bovine, gammaglobulin as the second antibody.

Microorganisms. Virulent $L$. pneumophila Philadelphia Type I, originally obtained from the Center for Disease Control, were passed in guinea pigs, harvested from spleen homogenates, and grown in albuminyeast extract (AYE) broth (17). By comparing direct counts of bacterial particles in a Petroff-Hausser chamber to colony forming units (cfu), we determined that the AYE broth-grown organisms were $78-86 \%$ viable. They retained full virulence as determined by lethality to guinea pigs. A strain of $L$. pneumophila, type I, that had been repeatedly passed on Mueller-Hinton and charcoal-yeast extract agar for 2 yr and was avirulent for guinea pigs was obtained from Dr. Richard L. Friedman, University of Oregon Health Sciences Center, Portland, OR. These organisms also were grown on AYE broth. The number of cfu per milliliter was determined by the growth of either the virulent or avirulent $L$. pneumophila on AYE agar.

For preparation of radiolabeled $L$. pneumophila, $50 \mu \mathrm{l}$ of a frozen splenic homogenate in phosphate-buffered saline, pH 7.0 (PBS), containing 1-2.5 $\times 10^{4} \mathrm{cfu}$ of virulent $L$. pneumophila or an equal number of the avirulent organisms, were added to $5 \mathrm{ml}$ of AYE broth containing $2.5 \mu \mathrm{Ci},\left[{ }^{35} \mathrm{~S}\right] \mathrm{L}$-cysteine in $15-\mathrm{ml}$ tubes. The tubes were tumbled in a rotary rack (Roto-Rack, Fischer Scientific Co., Pittsburgh, PA) 50 times/ $\min$ at $37^{\circ} \mathrm{C}$. When the organisms had reached stationary phase (28$36 \mathrm{~h}$ after inoculation), they were washed three times with cold $\left(4^{\circ} \mathrm{C}\right)$ PBS by centrifugation at $4000 \mathrm{~g}$ for $15 \mathrm{~min}$. The pelleted organisms were resuspended to an optical density of 0.15 at $490 \mathrm{~nm}\left(\sim 1 \times 10^{8}\right.$ $\mathrm{cfu} / \mathrm{ml}$ ) in PBS and immediately placed on ice. Gram stains of these cultures revealed only small, faintly stained gram-negative coccobacilli. The number of cfu in suspensions of radiolabeled and unlabeled Legionella of similar optical density were comparable. Virulent $L$. pneumophila grown and processed in this manner or in spleen homogenates were lethal to guinea pigs following intraperitoneal injection of comparable numbers of bacteria. Thus, as determined by lethality to guinea pigs, $L$. pneumophila grown in AYE broth retained virulence. None of four guinea pigs inoculated with $\sim 5 \times 10^{8} \mathrm{cfu}$ of the agar-passed Legionella died, which supported the avirulent nature of this strain (17).

Escherichia coli. ATCC 11775 was maintained by monthly passage on Trypticase soy agar and grown overnight in Trypticase soy broth before use. For preparation of radiolabeled organisms, $50 \mu \mathrm{l}$ was inoculated into $5 \mathrm{ml}$ of a chemically defined medium (22) that was modified by omitting agar and L-leucine and by adding $5 \mu \mathrm{g} / \mathrm{ml}$ of riboflavin, 5 $\mu \mathrm{g} / \mathrm{ml}$ of thioctic acid, and $2.5 \mu \mathrm{Ci}$ of $\left[{ }^{14} \mathrm{C}\right]$ leucine, and the mixture was incubated overnight at $37^{\circ} \mathrm{C}$. Organisms were then washed and processed as described for L. pneumophila.

\section{Antimicrobial activity of $A M$ against L. pneumophila, and $E$. coli}

Cell preparations containing $5 \times 10^{5} \mathrm{AM}$ in $0.5 \mathrm{ml}$ of M199+FCS (that contained penicillin and streptomycin) were placed in $16-\mathrm{mm}$ wells of Linbro trays (Linbro Scientific, Inglewood, CA). After incubation for 2-4 h, nonadherent cells were removed by washing six times with HBSS containing $\mathrm{Ca}^{++}$and $\mathrm{Mg}^{++}$; these monolayers were $>98 \% \mathrm{AM}$. Fresh medium was added and monolayers were incubated for $18-42 \mathrm{~h}$ at $37^{\circ} \mathrm{C}$ in $5 \% \mathrm{CO}_{2}$. At least $4 \mathrm{~h}$ before the addition of organisms, the monolayers were washed six times with HBSS, and M199+FCS without antibiotics was added. In preliminary experiments, AM were cultured in antibioticfree medium for the entire period after removal of nonadherent cells 
with comparable results. AM monolayers cultured for $4 \mathrm{~h}$ in an antibioticfree medium and then lysed with $0.1 \%$ Triton X-100 did not inhibit the growth of $L$. pneumophila in AYE broth.

${ }^{35} \mathrm{~S}-\mathrm{L}$. pneumophila or ${ }^{14} \mathrm{C}-\mathrm{E}$. coli were diluted in M199 to a concentration of $\sim 10^{7}$ bacteria/ $/ \mathrm{ml}$ and $0.5 \mathrm{ml}$ was added to wells containing AM monolayers ( 10:1 organisms to AM ratio). After incubation for $30 \mathrm{~min}$ at $37^{\circ} \mathrm{C}$ (phagocytic period) the wells were washed eight times with HBSS. One set of triplicate wells was processed immediately (30min values) and $0.5 \mathrm{ml}$ of M199+FCS without antibiotics was added to the remainder. Incubation was continued for an additional $30 \mathrm{~min}$ (60-min values) or $90 \mathrm{~min}$ (120-min values). At each time point, the medium was removed by aspiration and $0.5 \mathrm{ml}$ of $0.1 \%$ Triton X-100 was added at $4^{\circ} \mathrm{C}$ to lyse the monolayers; this was repeated and the two aliquots were pooled. Complete lysis was confirmed by inverted phasecontrast microscopy. In preliminary experiments, $0.1 \%$ Triton X-100 did not affect bacterial viability. A $0.5-\mathrm{ml}$ aliquot of each AM monolayer lysate was added to $10 \mathrm{ml}$ of Aquasol-2 (New England Nuclear) in liquid scintillation vials and counted in a liquid scintillation spectrometer. A second $0.1-\mathrm{ml}$ aliquot was serially diluted in phosphate buffered saline containing $0.1 \%$ gelatin (PBSG) and cultured on AYE agar $(L$. pneumophila) or Trypticase soy agar (E. coli). A third $0.1-\mathrm{ml}$ aliquot was assayed for protein by a modification of the method of Lowry, Dulley et al. (23), using bovine serum albumin as the standard, to determine monolayer density.

Bacteria prepared as described above also were added to wells without AM monolayers and at zero time and at each time point the contents of duplicate wells were aspirated, centrifuged at $2000 \mathrm{~g}$ for $10 \mathrm{~min}$, washed once with HBSS, and the organisms were resuspended in 1.0 $\mathrm{ml}$ of $0.1 \%$ Triton $\mathrm{X}-100$ at $4^{\circ} \mathrm{C}$; aliquots were removed for measurement of radioactivity and viable bacteria, as described above. These wells served as growth controls.

In studies of the effect of oxygen metabolite scavengers and of methylamine on the killing of $L$. pneumophila by AM, the agents were added to the monolayers $4 \mathrm{~h}$ before the addition of the bacteria to allow uptake by the AM (24). The monolayers were then washed six times with HBSS, ${ }^{35}$ S-labeled Legionella was added, and the antimicrobial assay was performed. In some experiments with each inhibitor, the agents were present both before and during the assay, with comparable results.

Total AM-associated bacteria was determined by dividing the radioactivity (cpm) of each AM monolayer by the cpm per bacteria; the latter was determined by dividing the radioactivity (cpm) of the initial challenge suspension (growth control, time zero) by the number of viable organisms (cfu) in that suspension. Greater than $80 \%$ of the organisms in the initial challenge suspension were viable. The fraction of ingested organisms that survived intracellularly was determined by dividing the number of viable bacteria in the AM monolayer lysate by the total number of AM-associated bacteria at that time point. This fraction was divided by the ratio of viable to total bacteria in the corresponding growth control wells (corrected fraction survival) to correct for a change in the proportion of live to total organisms unrelated to killing by AM. The decrease in the proportion of viable organisms in the control wells during the $120-\mathrm{min}$ incubation period was $<18 \%$ in all experiments. The percentage of bacteria killed by AM was then determined as follows: percentage killed $=(1-$ corrected fraction survival $) \times 100$. In each experiment, bacteria recovered from representative AM monolayer lysates were determined to be $L$. pneumophila because of their failure to grow on Trypticase soy agar and because of microscopic examination of gram stains of random colonies grown on AYE agar. In some experiments, the identity of organisms was also confirmed by their staining with fluorescein-conjugated $L$. pneumophila antiserum (25).

To determine if intracellular degradation of Legionella and release of ${ }^{35} \mathrm{~S}$ from the monolayer into the supernatant occurred during the incubation, with resultant underestimation of AM-associated bacteria, samples of each monolayer supernatant (before AM lysis) were filtered through 0.2- $\mu \mathrm{m}$ millipore filters (Millipore Corp., Boston, MA) and assayed for radioactivity. Radioactivity released into the supernatant was $<10 \%$ of the monolayer-associated radioactivity at each time point.

Killing of AM-associated L. pneumophila was also assessed by a second method in which unlabeled organisms were centrifuged onto AM monolayers at $4^{\circ} \mathrm{C}$ (cold centrifugation method). Monolayers were established as described above. Legionella were grown in AYE broth with nonradiolabeled L-cysteine, washed three times with cold $\left(4^{\circ} \mathrm{C}\right)$ PBS, and resuspended in M199. One-half milliliter $\left(\sim 1 \times 10^{7}\right.$ organisms) was added to the monolayers and the mixtures were centrifuged at $4^{\circ} \mathrm{C}$ for $5 \mathrm{~min}$ at $125 \mathrm{~g}$. One set of triplicate monolayers was washed ten times with $\mathrm{HBSS}$ and processed immediately $(0 \mathrm{~min}$ values). The remainder were warmed for $5 \mathrm{~min}$ in a $37^{\circ} \mathrm{C} \mathrm{CO}_{2}$ incubator to $\sim 22^{\circ} \mathrm{C}$ and then washed ten times with $\mathrm{HBSS}$. One set was processed immediately (5-min values) and warm $\left(37^{\circ} \mathrm{C}\right) \mathrm{M} 199$ was added to the remaining two sets. Incubation was continued for an additional $5 \mathrm{~min}$ (10-min values) or $15 \mathrm{~min}$ (20-min values). At each time point, the medium was removed by aspiration and $0.5 \mathrm{ml}$ of $0.05 \%$ Triton X-100 in PBS was added at $4^{\circ} \mathrm{C}$. This was repeated, and the pooled lysates were sonicated for $10 \mathrm{~s}$ at a setting of one in a Heat Systems sonifier (Heat Systems Ultrasonics, Inc., Plainview, NY), and then were serially diluted and cultured as described above.

Monolayer cell number and the number of cell-associated bacteria were also estimated microscopically in representative experiments. Monolayers were grown on coverslips and, following infection with bacteria, the number of AM and intracellular organisms were estimated using Diff-Quik-stained monolayers and a calibrated ocular grid.

$N B T$ reduction by $A M$ phagocytosing $L$. pneumophila. To examine the ability of ingested Legionella to trigger the respiratory burst, AM adherent to glass coverslips were challenged with Legionella or opsonized zymosan $(0.1 \mathrm{mg} / \mathrm{ml})$ in M199+FCS in the presence of $1 \mathrm{mg} / \mathrm{ml} \mathrm{NBT}$. NBT reduction was determined microscopically and quantitatively as previously described (24).

Intracellular reptication of virulent and avirulent L. pneumophila in $A M$. Replication of virulent and avirulent Legionella within AM was assessed quantitatively and by fluorescent and electron microscopy. In the quantitative method, Legionella were grown overnight in AYE broth with nonradiolabeled L-cysteine. The organisms were washed three times with cold $\left(4^{\circ} \mathrm{C}\right) \mathrm{PBS}$ at $4,000 \mathrm{~g}$ for $15 \mathrm{~min}$ and were added to $\mathrm{AM}$ monolayers at a 10:1 organism to $\mathrm{AM}$ ratio or to wells not containing $\mathrm{AM}$ (growth controls). The monolayers were incubated at $37^{\circ} \mathrm{C}$ for 60 min and then washed eight times with HBSS to remove extracellular organisms. One set of monolayers was processed immediately, then M199+10\% FCS without antibiotics was added to the remaining monolayers and incubation was continued for $24,48,72,96$, and 120 h. At each time point, triplicate monolayers were lysed with $0.1 \%$ Triton $\mathrm{X}-100$ as described above; a $0.1-\mathrm{ml}$ aliquot was diluted in PBSG and cultured on AYE agar and a $0.1-\mathrm{ml}$ aliquot was assayed for protein content. Monolayer cell number and bacterial replication were also estimated for each experiment by counting the number of AM and bacteria on stained coverslips using a calibrated ocular grid.

In parallel with certain of these experiments, AM monolayers on glass coverslips or in 60-mm Petri dishes (Corning Glass Works, Corning, 
NY) were infected with virulent Legionella. At each time point coverslip monolayers were washed, fixed in methanol, stained with fluoresceinconjugated $L$. pneumophila antiserum (Center for Disease Control), and examined with a Zeiss epi-illumination fluorescence microscope (5). Other monolayers in Petri dishes were washed and fixed in $2.5 \%$ glu-

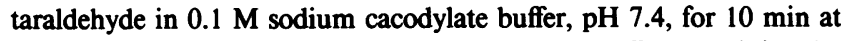
$4^{\circ} \mathrm{C}$. They were then washed twice in cacodylate buffer containing $7 \%$ sucrose, and processed for electron microscopy (26).

Statistics. Values are expressed as the mean \pm SE. The significance of differences between the means was determined by two-tailed $t$ test for independent means or by paired $t$ test (27).

\section{Results}

Antimicrobial effect of AM on L. pneumophila. As determined by uptake of radiolabeled organisms, similar numbers of virulent $\left(4.5 \pm 0.5 \times 10^{4}\right.$ per well, $\left.n=6\right)$ and avirulent $\left(3.7 \pm 0.6 \times 10^{4}\right.$ per well, $n=3$ ) L. pneumophila are AM-associated when incubated for $30 \mathrm{~min}$ with monolayers in the absence of specific antibody (Fig. $1 \mathrm{~A}$ ). The monolayers were washed at $30 \mathrm{~min}$ to remove non-AM-associated organisms and thus terminate phagocytosis, and incubation was continued for a further 30 and $90 \mathrm{~min}$. The total number of AM-associated bacteria remained constant during this period. After the initial 30-min incubation, $97.5 \pm 0.5 \%(n=6)$ of virulent and $97.8 \pm 0.2 \%(n$ = 3) of avirulent AM-associated Legionella were nonviable, and continued incubation of washed monolayers for 30 or $90 \mathrm{~min}$
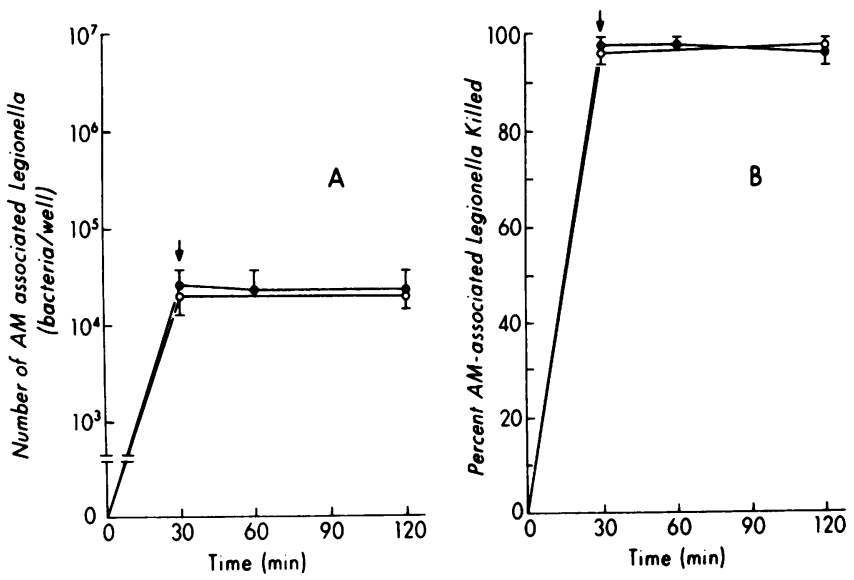

Figure 1. Uptake and killing of Legionella by AM by the radiolabeled bacteria method. AM monolayers $\left(\sim 3 \times 10^{5}\right.$ cells) were infected with $\sim 3 \times 10^{6}$ virulent $(\bullet)$ or avirulent $(0)$ Legionella in M199+FCS without antibiotics. After a 30-min incubation (arrow), the cells were washed and incubation continued in fresh medium. The cells were processed at the indicated time points as described in Methods. Monolayers infected with virulent Legionella (3.4 \pm 0.6 $\times 10^{5} \mathrm{AM} ; 42.7 \pm 9.7 \mu \mathrm{g}$ protein) were comparable in cell number and protein content to monolayers infected with avirulent organisms $\left(3.1 \pm 0.3 \times 10^{5} \mathrm{AM} ; 41.9 \pm 6.8 \mu \mathrm{g}\right.$ protein). Each point represents the mean $\pm S E$ of three (30- and 120-min avirulent and 60 -min virulent) or six (30- and 120-min virulent) experiments, each with replicate wells. $A$ indicates the number of AM-associated Legionella and $B$ indicates the percentage of the AM-associated Legionella killed. did not significantly increase the percentage killed (Fig. $1 \mathrm{~B}$ ). At each time point, $>90 \%$ of the bacteria of the washed monolayers were AM-associated, based on light microscopic assessment of stained monolayers. At $30 \mathrm{~min}, 10.5 \pm 0.8 \%$ of AM were infected and infected AM contained $1.3 \pm 0.4$ bacteria per cell (range 1-3). In representative experiments, most AM-associated bacteria were intracellular, based on electron microscopic assessment (not shown). Each monolayer contained $\sim 3 \times 10^{5}$ AM. Thus, the total number of AM-associated bacteria estimated microscopically at $30 \mathrm{~min}$ was $4 \times 10^{4}$, which is similar to that determined by monolayer radioactivity. In three parallel experiments, AM phagocytosed comparable numbers of $E$. coli $\left(4.6 \pm 0.5 \times 10^{4}\right.$ per monolayer) and virulent $L$. pneumophila (4.9 $\pm 0.4 \times 10^{4}$ per monolayer) during the 30 -min incubation period. However, only $78.2 \pm 2.1 \%$ of AM-associated $E$. coli were killed, compared with $97.0 \pm 0.5 \%$ of AM-associated Legionella $(P<0.05)$. The cell number and protein content of monolayers that were infected with $E$. coli or L. pneumophila were comparable (data not shown).

Results obtained by the cold centrifugation assay are shown in Fig. 2. Comparable numbers of virulent and avirulent Legionella were $\mathrm{AM}$-associated after centrifugation and repeated washing at $4^{\circ} \mathrm{C}\left(0.9 \pm 0.7 \times 10^{5}\right.$ and $1.7 \pm 1.0 \times 10^{5}$ for virulent and avirulent organisms, respectively). After incubation at $37^{\circ} \mathrm{C}$ for $5 \mathrm{~min}$, the temperature of the medium rose to $\sim 22^{\circ} \mathrm{C}$, and a decrease in cfu was detected with both virulent and avirulent organisms. Continued incubation for an additional $5 \mathrm{~min}$ at $37^{\circ} \mathrm{C}$ resulted in a further fall in cfu. Approximately $60 \%$ of the AM-associated Legionella were killed at this time period with no further loss of viability with an additional 10-min incubation at $37^{\circ} \mathrm{C}$. The percentage of virulent and avirulent Legionella killed was not significantly different at each time period. The percentage of AM-associated $E$. coli killed was $3.7 \pm 1.9,41.3 \pm 11.4$, and $39.0 \pm 1.2 \%$ at 5,10 , and $20 \mathrm{~min}$, respectively, under comparable incubation conditions.

$N B T$ reduction by $A M$-associated L. pneumophila. On microscopic examination, $95.6 \pm 2.4 \%(n=3)$ of ingested Legionella were coated with blue-black deposits of reduced NBT, as compared with $98.7 \pm 0.2 \%(n=2)$ of ingested opsonized zymosan; however, the density of the formazan deposits coating zymosan was greater than that coating Legionella. Legionella alone did not reduce NBT. When assayed quantitatively, AM alone reduced $9.5 \pm 1.9 \mathrm{nmol} \mathrm{NBT} / 10^{6} \mathrm{AM}$ per $30 \mathrm{~min}$. When stimulated by ingestion of virulent Legionella, avirulent Legionella, or $E$. coli, the increment in NBT reduction compared with controls, was $7.2 \pm 1.9,8.0 \pm 2.0$, or $28.1 \pm 1.1 \mathrm{nmol} \mathrm{NBT} / 10^{6} \mathrm{AM}$ per 30 min, respectively.

Effects of oxygen metabolite scavengers and methylamine on antimicrobial activity of $A M$. The effects of oxygen metabolite scavengers on killing of virulent Legionella by $A M$ is shown in Table I. The addition of SOD $(2.5 \mathrm{mg} / \mathrm{ml})$ or catalase $(2.5 \mathrm{mg} /$ $\mathrm{ml}$ ) alone to AM monolayers $4 \mathrm{~h}$ before addition of bacteria did not significantly effect AM killing of Legionella during a subsequent 30-min incubation period. However, when both SOD and catalase were added, killing of Legionella by AM was sig- 


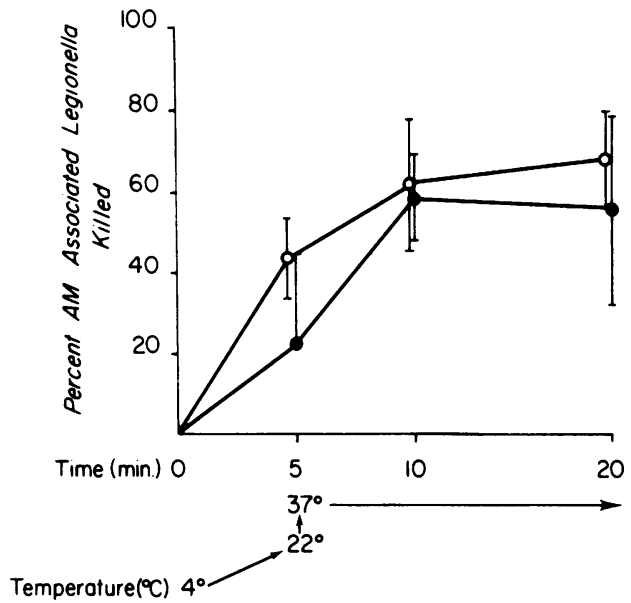

Figure 2. Killing of AM-associated Legionella by the cold centrifugation method. Virulent $(\bullet)$ or avirulent $(0)$ Legionella $\left(\sim 1 \times 10^{7}\right)$ were centrifuged onto AM monolayers at $125 \mathrm{~g}$ for $5 \mathrm{~min}$ at $4^{\circ} \mathrm{C}$. Then monolayers were washed, warmed, and assayed for viable bacteria as described in Methods. Monolayer protein contents were comparable at each time period. Values are the mean of three (virulent) or four (avirulent) experiments each with triplicate monolayers.

nificantly decreased. This inhibition of bactericidal activity was not observed when heat-treated SOD plus active catalase or active SOD plus heat-treated catalase were employed. The hydroxyl radical scavenger mannitol at $50 \mathrm{mM}$ concentration also inhibited the killing of Legionella by AM under these conditions.

Table I. Effect of Oxygen Radical Scavengers and Methylamine on the Killing of Legionella by $A M^{*}$

\begin{tabular}{ll}
\hline Supplements & $\begin{array}{l}\text { Percent AM-associated } \\
\text { Legionella killed }\end{array}$ \\
\hline None & $96.4 \pm 0.5(11) \ddagger$ \\
$\mathrm{SOD}(2.5 \mathrm{mg} / \mathrm{ml})$ & $95.3 \pm 0.3(3)$ \\
Catalase $(2.5 \mathrm{mg} / \mathrm{ml})$ & $97.0 \pm 0.5(3)$ \\
$\mathrm{SOD}+$ catalase & $71.1 \pm 1.8(4)<0.001 \S$ \\
$\mathrm{SOD}+$ catalase $($ heated $)$ & $91.5 \pm 1.7(2)$ \\
$\mathrm{SOD}($ heated $)+$ catalase & $92.9 \pm 2.6(2)$ \\
Mannitol $(50 \mathrm{mM})$ & $52.0 \pm 3.2(3)<0.001$ \\
$\mathrm{Na}_{2} \mathrm{SO}{ }_{4}(50 \mathrm{osmol})$ & $93.1 \pm 1.8(2)$ \\
Methylamine $(10 \mathrm{mM})$ & $96.5 \pm 1.8(2)$ \\
Methylamine $(25 \mathrm{mM})$ & $92.0 \pm 2.1(2)$
\end{tabular}

* The reaction mixture was as described in Fig. 1 except that only virulent $L$. pneumophila were employed, incubation was for $30 \mathrm{~min}$, and the supplements were added to monolayers $4 \mathrm{~h}$ before the assay at the concentrations indicated. Catalase was heated at $100^{\circ} \mathrm{C}$ for 15 min and SOD was heated at $120^{\circ} \mathrm{C}$ for $15 \mathrm{~min}$ where indicated. $¥$ Mean \pm SD (number of experiments).

$\S$ Probability value for the difference from control (none) where significant. All other values are $P>0.05$.
The effect of mannitol was significantly greater than that of SOD + catalase $(P<0.01)$. An equiosmolar amount of sodium sulfate could not replace mannitol in the inhibition of AM killing of Legionella. The incubation of AM with 10 and 25 $\mathrm{mM}$ methylamine, which raises lysosomal $\mathrm{pH}(28)$, did not significantly affect their ability to kill Legionella under our experimental conditions.

Intracellular replication of virulent and avirulent L. pneumophila in $A M$. The number of viable Legionella in monolayers was determined at $1,24,48,72,96$, and $120 \mathrm{~h}$, which followed the fate of the virulent and avirulent Legionella that survived early intracellular killing by AM (Fig. 3). Although comparable numbers of viable avirulent and virulent Legionella were AMassociated after the 1-h phagocytosis period, by $24 \mathrm{~h}$, intracellular replication of virulent Legionella was significantly greater than that of the avirulent organisms, $(P<0.025)$ and virulent Legionella continued to replicate at a greater rate over a $96-\mathrm{h}$ period of incubation (Fig. 3). Monolayers infected with avirulent and virulent Legionella were comparable in cell number and protein content at these time points. The increased rate of replication of virulent as compared with avirulent Legionella in primate AM was supported by microscopic examination of monolayers. At $1 \mathrm{~h}$, the percentage of infected AM and the mean number of bacteria per cell were comparable for both virulent and avirulent organisms (11\% of AM infected, 1.3 organisms per infected cell and $12 \%$ AM infected, 1.5 organisms

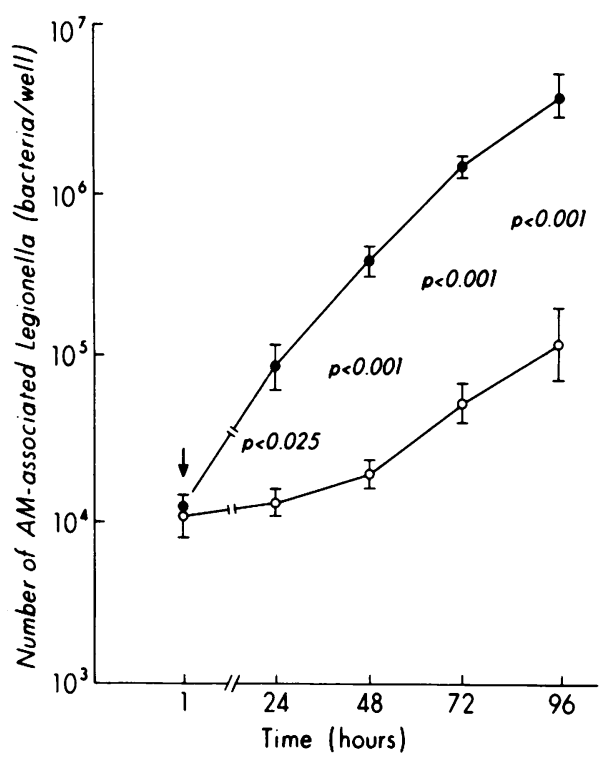

Figure 3. Replication of $L$. pneumophila in primate AM. Virulent (•) and avirulent ( $(0)$ Legionella were added to $A M$ in parallel at a 10:1 ratio. After a 1-h phagocytosis period, the monolayers were washed, fresh medium was added, and incubation was continued. At 1, 24, 48,72 , and $96 \mathrm{~h}, \mathrm{AM}$ monolayers were lysed and the colony forming units determined. The results are the mean $\pm \mathrm{SE}$ of three experiments. The probability values for the difference between virulent and avirulent Legionella are shown. 
per infected cell, respectively). However, at $72 \mathrm{~h}$ with virulent Legionella, $93 \%$ of AM were infected with a mean of 9.2 organisms per cell, whereas with avirulent organisms, $74 \%$ of AM were infected with a mean of 4.2 Legionella per cell. By $120 \mathrm{~h}$, replication of virulent Legionella resulted in monolayer destruction, whereas monolayers infected with avirulent Legionella remained intact. The number of Legionella in growth control wells not containing AM did not change over the 96-h incubation period employed in Fig. $3\left(3.6 \times 10^{6} \mathrm{cfu} / \mathrm{ml}\right.$ at $1 \mathrm{~h} ; 3.2 \times 10^{6}$ $\mathrm{cfu} / \mathrm{ml}$ at $96 \mathrm{~h}$ )

Intracellular survival and replication of virulent Legionella in AM was supported by direct fluorescent antibody staining (Fig. 4) and by electron microscopic examination of AM monolayers at $1 \mathrm{~h}$ (Fig. $5 \mathrm{~A}$ ) and $48 \mathrm{~h}$ (Fig. 5, $B$ and $C$ ) after infection. At $1 \mathrm{~h}$, most infected cells contained a single organism in a membrane-bound vacuole (Fig. $5 A$ ). After $48 \mathrm{~h}$ in culture, the majority of cells were heavily infected with multiple organisms per vacuole (Fig. $5, B$ and $C$ ). We did not detect a clustering of ribosomes around phagosomes (5) in our preparations.

\section{Discussion}

In this paper we report: $(a)$ that primate $\mathrm{AM}$ ingest and kill virulent and avirulent Legionella pneumophila Philadelphia Type I equally in the absence of specific antibody; $(b)$ that this bactericidal activity is due at least in part to hydroxyl radicals; $(c)$ that organisms that survive replicate intracellularly, and $(d)$ that virulent Legionella replicate more rapidly than do avirulent organisms.

Under our experimental conditions, primate AM phagocytosed comparable numbers of virulent and avirulent Legionella in the absence of type-specific antiserum; quantitative uptake of radiolabeled bacteria and microscopic evaluation indicated that $\sim 10 \%$ of AM ingested one to two Legionella during the 30 -min phagocytic period. This represented $\sim 1 \%$ of the organisms added to the monolayers. Other workers have found that human blood monocytes (5), rat peritoneal macrophages and rat AM (8), guinea pig peritoneal macrophages (7) and cynomolgus monkey AM (6), phagocytose $L$. pneumophila, type $\mathrm{I}$, in the absence of antibody, but that phagocytosis is significantly enhanced by type-specific antibody. Although healthy adult monkeys may have L. pneumophila antibody (29), the phagocytosis that we observed could not be explained by such a mechanism since each of the animals we studied lacked detectable L. pneumophila antibody (titer $<1: 32$ ). We chose to evaluate the effects of AM on Legionella in the absence of antibody, since detectable levels of antibody are usually not present in humans at the onset of infection (14).

Ingested Legionella were highly susceptible to the antimicrobial systems of primate AM. By the each of two methods, the majority of AM-associated Legionella were killed, with virulent and avirulent Legionella being comparably susceptible. In contrast, fewer-AM associated $E$. coli were killed under comparable conditions. Apparent killing of Legionella by primate
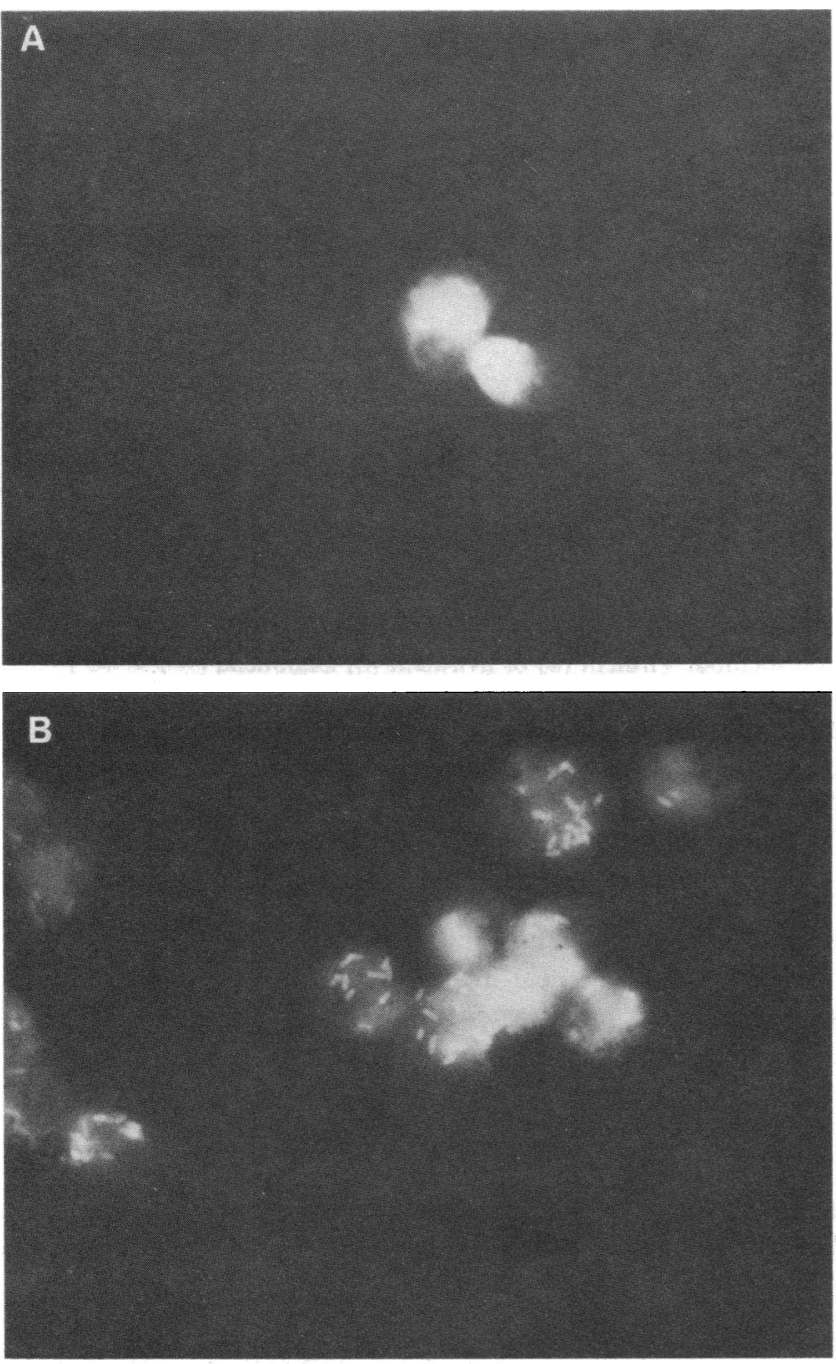

Figure 4. Replication of virulent L. pneumophila in AM. L. pneumophila was added at a 10:1 bacteria/AM ratio for $1 \mathrm{~h}$ at $37^{\circ} \mathrm{C}$; monolayers were then washed vigorously and either immediately fixed and stained with fluorescein-conjugated rabbit anti-L. pneumophila type 1 antiserum $(A)$ or reincubated for $48 \mathrm{~h}(B)$ before processing. $(\times 1,000)$

AM was 95\%, using the radiolabeled bacteria method, and $\sim 60 \%$ using the cold centrifugation assay. Because AM-associated bacteria, as estimated by radioactivity, does not distinguish between viable and dead labeled organisms, the assay using radiolabeled bacteria would have overestimated the percentage killed if the AM preferentially phagocytosed the nonviable bacteria $(\sim 20 \%)$ in the initial infecting inoculum. In the cold centrifugation method, AM-associated bacteria at zero time are determined to be viable organisms (cfu) after centrifugation of the bacteria onto the monolayer at $4^{\circ} \mathrm{C}$. The progressive fall in viable organisms during the succeeding $10 \mathrm{~min}$ of incubation 

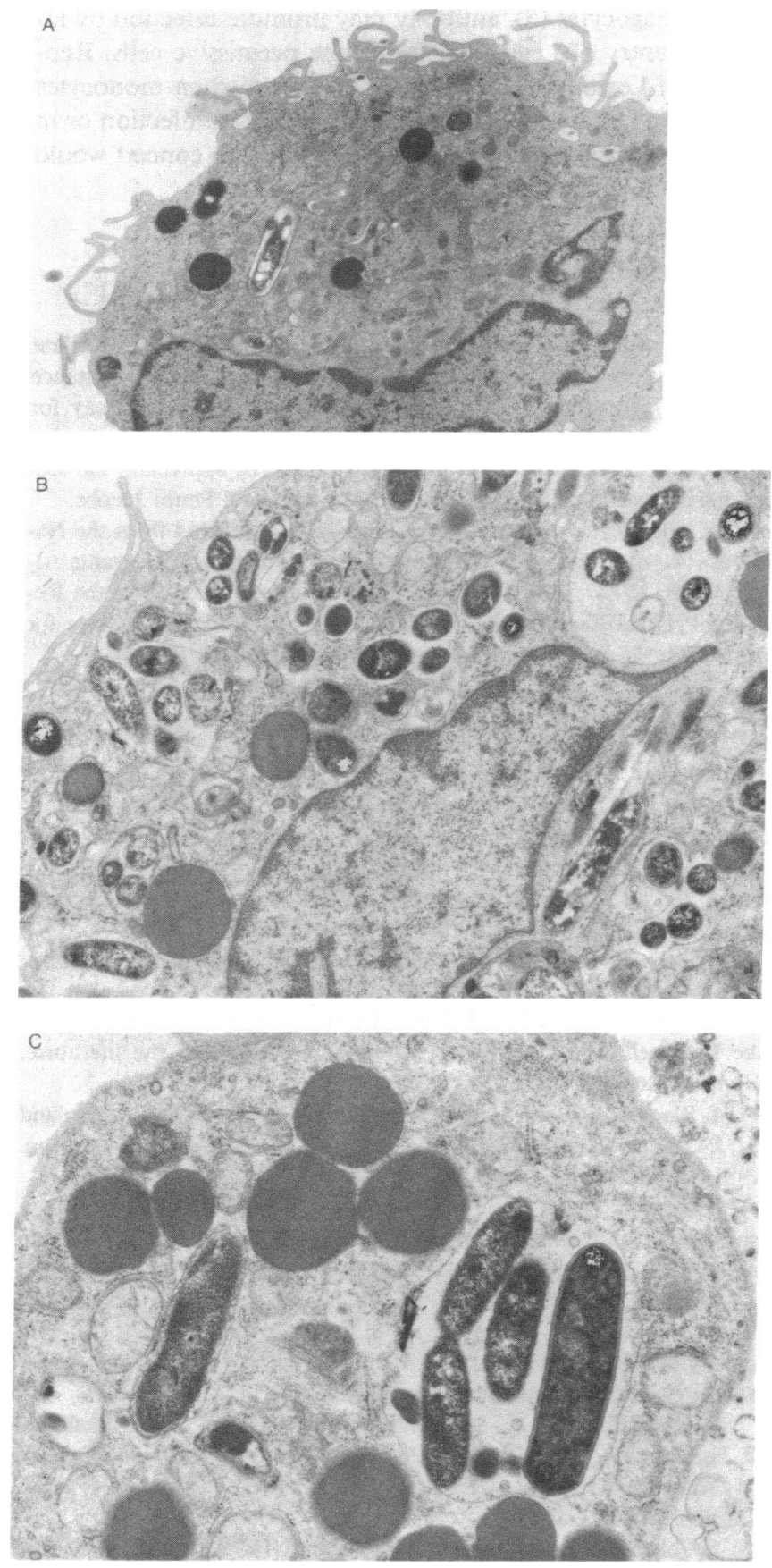

Figure 5. Electron micrographs of AM infected with virulent $L$. pneumophila. Monolayers were infected at an 10:1 bacteria/AM ratio for $1 \mathrm{~h}$ at $37^{\circ} \mathrm{C}$. After vigorous washing, one set of monolayers was fixed in $2.5 \%$ glutaraldehyde and processed for electron microscopy $(A, \times 12,000)$, and the remainder were incubated at $37^{\circ} \mathrm{C}$ for $48 \mathrm{~h}$ and then processed $(B, \times 18,600)$. $C$ demonstrates Legionella organisms dividing within an $\mathrm{AM}$ phagosome at $48 \mathrm{~h}(\times 23,000)$. The identity of these organisms was confirmed by their staining with fluorescein-conjugated $L$. pneumophila type I antiserum. at raised temperatures confirms the killing of Legionella by the primate AM.

Recent reports have implicated reactive oxygen metabolites, formed by the respiratory burst, in the antimicrobial effect of mononuclear phagocytes on intracellular protozoan pathogens (24, 30-36). Reduction of NBT to blue-black formazan, visualized microscopically as a ring of NBT-positive material around organisms within macrophage phagosomes, has been employed as a measure of the respiratory burst $(24,34)$. Phagocytosis of Legionella by primate AM is associated with a respiratory burst, as indicated by localized reduction of NBT around the ingested organism. When assayed quantitatively, phagocytosis of Legionella stimulated NBT reduction by AM that was consistent but less than that stimulated by $E$. coli. This prompted a study of the role of oxygen metabolites in the killing of Legionella by primate AM. A combination of SOD and catalase significantly reduced the killing of virulent Legionella by $A M$, whereas each enzyme alone was ineffective. Both SOD and catalase exhibit a high degree of specificity for their respective substrates (37), suggesting that neither $\mathrm{O}_{2}^{-}$or $\mathrm{H}_{2} \mathrm{O}_{2}$ alone but rather products of their interaction are mediators of $\mathrm{AM}$ anti-Legionella activity. $\mathrm{O}_{\overline{2}}^{\overline{2}}$ and $\mathrm{H}_{2} \mathrm{O}_{2}$ interact in the presence of a trace metal catalyst, such as iron, to generate hydroxyl radicals $(\mathrm{OH} \cdot)$ and possibly singlet oxygen $\left({ }^{1} \mathrm{O}_{2}\right)$ (Haber-Weiss reaction); these products have antimicrobial activity $(38,39)$. Mannitol $(50 \mathrm{mM})$, which is a potent scavenger of $\mathrm{OH} \cdot(40)$, inhibited the killing of Legionella by $\mathrm{AM}$, an effect that was not due to its osmotic activity, since the inhibition was not reproduced by an equiosmolar amount of $\mathrm{Na}_{2} \mathrm{SO}_{4}$. These findings taken together suggest that $\mathrm{OH} \cdot$ play a role in the early killing of Legionella by AM. This is supported by our finding that the cell-free xanthine oxidase system is toxic to both virulent and avirulent Legionella, in part through the formation of hydroxyl radicals (17). We have also found that Legionella are more sensitive than our $E$. coli strain to the toxic effect of $\mathrm{H}_{2} \mathrm{O}_{2}$ and of oxygen metabolites generated by the xanthine oxidase system. The difference in susceptibility of Legionella and $E$. coli to killing by AM and by oxygen metabolites, correlated with the significantly lower content of the oxygen metabolite scavengers catalase, glutathione peroxidase, glutathione reductase, and glutathione in Legionella than in $E$. coli (17). It should be emphasized, however, that only partial protection resulted from the addition of mannitol or SOD plus catalase. This may be due in part to limited access of the scavengers to the site of microbial killing; however, the presence of a variety of antimicrobial systems in phagocytes $(41,42)$ raise the possibility that $\mathrm{OH} \cdot$ is but one of a number of anti-Legionella agents in AM. Methylamine, which raises lysosomal pH (28), did not affect AM killing of Legionella under our experimental conditions.

The mechanism of the survival of a fraction of both virulent and avirulent Legionella in AM was not determined by our studies. It seems unlikely that the killing mechanisms of AM were overwhelmed since, after the initial phagocytic period, most infected AM contained only one bacterium and none contained more than three; similarly, replication of Legionella 
in human monocytes occurs when they are infected at a bacteria to monocyte ratio of $\sim 1: 300(5,16)$. A subpopulation of cells which lack anti-Legionella activity may be present in our AM preparations, or there may be a subpopulation of inherently or developmentally resistant organisms present in our Legionella preparations. Our results do not favor a small subpopulation of nontoxic AM since, as determined by microscopic examination, for both virulent and avirulent organisms the percentage of infected AM increased from $\sim 10 \%$ at $1 \mathrm{~h}$ to $93 \%$ for virulent and $74 \%$ for avirulent Legionella at $72 \mathrm{~h}$. This suggests intracellular replication of Legionella in the initially infected AM with subsequent rupture, release of organisms, ingestion by, and replication in the majority of other AM. The demonstration of a subpopulation of resistant Legionella must await isolation and investigation of Legionella released by infected AM.

Legionella that survive early killing by AM replicate; however, in contrast to the comparable susceptibility of virulent and avirulent organisms to the bactericidal activity of AM, virulent Legionella replicate much more rapidly than do avirulent organisms. Under our conditions, intracellular replication of virulent Legionella resulted in destruction of the monolayers by $120 \mathrm{~h}$, whereas monolayers containing avirulent organisms remained intact. The difference between virulent and avirulent Legionella, which favors replication by the former, is unknown.

Our results suggest that virulence of Legionella does not correlate with susceptibility to killing by AM, but rather with the ability of those organisms that survive to replicate intracellularly. Other workers have found that virulent organisms replicate within each type of mononuclear phagocyte studied (5-8), and in fibroblasts (9), emphasizing the importance of intracellular replication as a marker of virulence. The property of virulence appears to be relatively stable in our Legionella strain, since the organisms remained virulent after more than 30 passages on AYE agar (17). However, loss of virulence has been noted when other strains have been serially passed on modified Mueller Hinton agar, and virulence can be reinduced by passage of the avirulent strains in fibroblasts (43). The avirulent strain we used was derived by serial passage of a virulent strain on modified Mueller Hinton agar. This raises the possibility of ready passage between the avirulent and virulent state in nature, with implications in regard to infectivity.

We did not observe the ribosomal clustering around vacuoles containing replicating Legionella that has been described after in vitro (5) and in vivo (44) infection, although ribosomes were clearly evident in other locations within the AM. This phenomenon is not a constant feature (44); the variability may reflect differences in the period of infection (45), the cell type, or the species of animal.

The studies reported here were performed in the absence of added antibody, and the findings would therefore be most applicable to early primary infection. Antibody is required for effective phagocytosis of Legionella by polymorphonuclear phagocytes (13), and promotes phagocytosis of Legionella by human monocytes $(15)$ and animal macrophages $(7,8)$. Since the virulent Legionella that survive replicate readily in mono- nuclear phagocytes (5), antibody may promote infection by facilitating entry of Legionella into these permissive cells. Replication of Legionella, however, is decreased when monocytes are activated by lymphokines (16). Thus, late in infection or in reinfection, antibody and lymphokines acting in concert would be expected to limit progression of the disease.

\section{Acknowledgments}

We are grateful to William M. Weaver and Judith Westall for excellent technical assistance, to Donald Chaffin and Dawn Shugarts for assistance in reagent preparation, to Judy Johnson and Susan Hemingway for assistance at the Regional Primate Center, and to Alice Yasutake for technical assistance with electron microscopy. We appreciate the secretarial assistance of Kae Pierce, Cheryl Steiner and Penni Jacobs.

Dr. Locksley is supported by training grant AI-07044 from the National Institutes of Health. This work is supported by NIH grants AI16760, HL-19187, and AI-07763. Tissues were obtained from the Regional Primate Research Center, University of Washington Center for the Health Sciences, which is supported by NIH grant RR0166.

\section{References}

1. Fraser, D. W., T. R. Tsai, W. Orenstein, W. E. Parkin, H. J. Beecham, R. G. Sharrar, J. Harris, G. F. Mallison, S. M. Martin, J. E. McDade, C. C. Shepard, P. S. Branchman, and the Field Investigation Team. 1977. Legionnaire's disease. Description of an epidemic of pneumonia. N. Engl. J. Med. 297:1189-1197.

2. Fraser, D. W., and J. E. McDade. 1979. Legionellosis. Sci. Am 241:82-99.

3. Winn, Jr., W. C., and R. L. Myerowitz. 1981. The pathology of the Legionella pneumonias: A review of 74 cases and the literature. Hum. Pathol. 12:401-422.

4. Blackmon, J. A., F. W. Chandler, W. B. Cherry, A. C. England III, J. C. Feeley, M. D. Hicklin, R. M. McKinney, and H. W. Wilkinson. 1981. Legionellosis. Amer. J. Pathol. 103:429-465.

5. Horwitz, M. A., and S. C. Silverstein. 1980. Legionnaire's disease bacterium (Legionella pneumophila) multiplies intracellularly in human monocytes. J. Clin. Invest. 66:441-450.

6. Kishimoto, R. A., M. D. Kastello, J. D. White, F. G. Shirey, V. G. McGann, E. W. Larson, and K. W. Hedlund. 1979. In vitro interaction between normal cynomolgus monkey alveolar macrophages and Legionnaire's disease bacteria. Infect. Immun. 25:761-763.

7. Kishimoto, R. A., J. D. White, F. G. Shirey, V. G. McGann, R. F. Berendt, E. W. Larson, and K. W. Hedlund. 1981. In vitro response of guinea pig peritoneal macrophages to Legionella pneumophila. Infect. Immun. 31:1209-1213.

8. Johnson, W., E. Pesanti, and J. Elliott. 1979. Serospecificity and opsonic activity of antisera to Legionella pneumophila. Infect. Immun. 26:698-704.

9. Wong, M. C., E. P. Ewing, Jr., C. S. Callaway, and W. L. Peacock, Jr. 1980. Intracellular multiplication of Legionella pneumophila in cultured human embryonic lung fibroblasts. Infect. Immun. 28:1014-1018.

10. Feeley, J. C., R. J. Gibson, G. W. Gorman, N. C. Langford, J. K. Rahseed, D. C. Mackel, and W. B. Baine. 1979. Charcoal-yeast extract agar: primary isolation medium for Legionella pneumophila. $J$. Clin. Micro. 10:437-441.

11. Feeley, J. C., G. W. Gorman, R. E. Weaver, D. C. Mackel, and 
H. W. Smith. 1979. Primary isolation media for Legionnaire's disease bacterium. J. Clin. Microbiol. 8:320-325.

12. Rehm, S. R., G. N. Gross, and A. K. Pierce. 1980. Early bacterial clearance from murine lungs; species-dependent phagocyte response. $J$. Clin. Invest. 66:194-199.

13. Horwitz, M. A., and S. C. Silverstein. 1981. Interaction of the Legionnaire's disease bacterium ( $L$. pneumophila) with human phagocytes. I. L. pneumophila resists killing by polymorphonuclear leukocytes, antibody, and complement. J. Exp. Med. 153:386-397.

14. Kirby, B. D., K. M. Synder, R. D. Meyer, and S. M. Finegold. 1978. Legionnaire's disease: clinical features of 24 cases. Ann. Intern. Med. 89:297-309.

15. Horwitz, M. A., and S. C. Silverstein. 1981. Interaction of the Legionnaire's disease bacterium (Legionella pneumophila) with human phagocytes. II. Antibody promotes binding of $L$. pneumophila to monocytes but does not inhibit intracellular multiplication. J. Exp. Med. 153:398-406.

16. Horwitz, M. A., and S. C. Silverstein. 1981. Activated human monocytes inhibit the intracellular multiplication of Legionnaire's disease bacteria. J. Exp. Med. 154:1618-1635.

17. Locksley, R. M., R. F. Jacobs, C. B. Wilson, W. M. Weaver, and S. J. Klebancff. 1982. Susceptibility of Legionella pneumophila to oxygen dependent microbicidal systems. J. Immunol. 129:2192-2197.

18. Wilson, C. B., and J. S. Remington. 1979. Activity of human blood leukocytes against Toxoplasma gondii. J. Infect. Dis. 140:890895.

19. Koski, I. R., D. G. Poplack, and R. M. Blaese. 1976. A nonspecific esterase stain for the identification of monocytes and macrophages. In In vitro Methods in Cellular Mediated and Tumor Immunity. B. R. Bloom and J. R. David, editors. Academic Press, Inc., New York. 359-362.

20. Kaplow, L. S. 1965. Simplified myeloperoxidase stain using benzidine dihydrochloride. Blood. 25:215-219.

21. Wilkinson, H. W., D. D. Cruce, B. J. Fikes, L. P. Yealy, and C. E. Farshy. 1979. Indirect immunofluorescence test for Legionnaire's disease. In Legionnaire's: The Disease, the Bacterium and Methodology. G. L. Jones and G. A. Hebert, editors. U. S. Department of Health, Education and Welfare, Public Health Service, Center for Disease Control, Bureau of Laboratories, Atlanta, GA. Publication No. (CDC) 79-8375. 111-116.

22. Catlin, B. W. 1973. Nutritional profiles of Neisseria gonorrheae, Neisseria meningitidis, and Neisseria lactamica in chemically defined media and the use of growth requirements for gonococcal typing. $J$. Infect. Dis. 128:178-194.

23. Dulley, J. R., and P. A. Grieve. 1975. A simple technique for elimination interference by detergents in the Lowry method. Anal. Biochem. 64:136-141.

24. Wilson, C. B., V. Tsai, and J. S. Remington. 1980. Failure to trigger the oxidative metabolic burst by normal macrophages. $J$. Exp. Med. 151:328-346.

25. Jones, G. L., and G. A. Hebert. G. L. Jones and G. A. Hebert, editors. 1979. Indirect immunofluorescence test for Legionnaires' disease. In Legionnaire's: The Disease, the Bacterium and Methodology. U. S. Department of Health, Education, and Welfare, Public Health Service, Center for Disease Control, Bureau of Laboratories, Atlanta, GA. Publication No. (CDC) 79-8375. 155-161.

26. Bodel, P. T., B. A. Nichols, and D. F. Bainton. 1977. Appearance of peroxidase reactivity within the rough endoplasmic reticulum of blood monocytes after surface adherence. J. Exp. Med. 145:264-274.
27. Snedecor, G. W., and W. G. Cochran. 1967. Statistical Methods. Iowa State University Press, Ames, IA. 66-116.

28. Ohkuma, S., and B. Poole. 1978. Fluorescence probe measurement of the intralysosomal $\mathrm{pH}$ in living cells and the perturbation of pH by various agents. Proc. Natl. Acad. Sci. USA. 75:3327-3331.

29. Helmke, R. J., S. S. Kalter, and R. L. Heberling. 1981. Distribution of Legionella pneumophila antibody among primate species. J. Clin. Microbiol. 13:508-512.

30. Murray, H. W., C. W. Juangbhanich, C. F. Nathan, and Z. A. Cohn. 1979. Macrophage oxygen-dependent antimicrobial activity. II. The role of oxygen intermediates. J. Exp. Med. 150:950-964.

31. Nathan, C., N. Noguera, C. Juangbhanich, J. Ellis, and Z. Cohn. 1979. Activation of macrophages in vivo and in vitro. Correlation between hydrogen peroxide release and killing of Trypanosoma cruzi. J. Exp. Med. 149:1056-1068.

32. Murray, H. W., and Z. Cohn. 1980. Macrophage oxygen-dependent antimicrobial activity. III. Enhanced oxidative metabolism as an expression of macrophage activation. J. Exp. Med. 152:1596-1609.

33. Murray, H. W., C. F. Nathan, and Z. A. Cohn. 1980. Macrophage oxygen-dependent antimicrobial activity IV. Role of endogenous scavengers of oxygen intermediates. J. Exp. Med. 152:1610-1624.

34. Murray, H. W. 1981. Susceptibility of Leishmania to oxygen intermediates and killing by normal macrophages. J. Exp. Med. 153:1302-1315.

35. Murray, H. W. 1981. Interaction of Leishmania with a macrophage cell line. Correlation between intracellular killing and the generation of oxygen intermediates. J. Exp. Med. 153:1690-1695.

36. Tanaka, Y., C. Kiyotaki, H. Tanowitz, and B. R. Bloom. 1982. Reconstitution of a variant macrophage cell line defective in oxygen metabolism with a $\mathrm{H}_{2} \mathrm{O}_{2}$-generating system. Proc. Natl. Acad. Sci. USA. 79:2584-2588.

37. McCord, J. M., and I. Fridovich. 1978. The biology and pathology of oxygen radicals. Ann. Intern. Med. 89:122-127.

38. Rosen, H., and S. J. Klebanoff. 1979. Bactericidal activity of a superoxide anion-generating system. A model for the polymorphonuclear leukocyte. J. Exp. Med. 149:27-39.

39. Rosen, H., and S. J. Klebanoff. 1981. Role of iron and ethylenediamine-tetraacetic acid in the bactericidal activity of a superoxide anion-generating system. Arch. Biochem. Biophys. 208:512-519.

40. Dorfman, L. M., and G. E. Adams. 1973. Reactivity of hydroxyl radical in aqueous solutions. Nat'l. Bureau Standards, U. S. Dept. Commerce (Wash. DC.). 1-58.

41. Root, R. K., and M. S. Cohen. 1981. The microbicidal mechanisms of human neutrophils and eosinophils. Rev. Infect. Dis. 3:565598.

42. Klebanoff, S. J. 1982. Oxygen-dependent cytotoxic mechanisms of phagocytes. In Advances in Host Defense Mechanisms. J. I. Gallin and A. S. Fauci, editors. Raven Press, New York. 1:111-162.

43. Wong, M. C., W. L. Peacock, R. M. McKinney, and K. H. Wong. 1981. Legionella pneumophila: avirulent to virulent conversion through passage in cultured human embryonic lung fibroblasts. Current Microbiol. 5:31-34.

44. Baskerville, A., A. B. Dowsett, R. B. Fitzgeorge, P. Hembleton, and M. Broster. 1983. Ultrastructure of pulmonary alveoli and macrophages in experimental Legionnaire's disease. J. Pathol. 140:77-90.

45. Horwitz, M. A. 1983. Formation of a novel phagosome by the Legionnaires' disease bacterium (Legionella pneumophila) in human monocytes. J. Exp. Med. 158:1319-1331. 